\title{
COHESIÓN TERRITORIAL, COMPETITIVIDAD Y RESPONSABILIDAD SOCIAL CORPORATIVA EN LA UNIÓN EUROPEA
}

\author{
Elena F. PÉREZ CARRILLO*
}

RESUMEN: La programación de ayudas estructurales en Europa a partir de 2007 ponen de manifiesto que los criterios de eficacia y competitividad que inspiran tradicionalmente una filosofía empresarial se están consolidando como criterios de asignación de recursos en la política de cohesión; por otra parte, el progresivo reconocimiento de las empresas, y en particular de las PYME como motores del mercado interior y de la integración europea, hace que la Unión Europea propugne la introducción de regímenes de ayuda y de gestión empresarial acordes con su función de agentes sociales de maximización de los beneficios, no sólo a favor de sus accionistas sino de la sociedad en general.

ABSTRACT: Programming of Structural aid in Europe after 2007 shows that efficacy and competivity which have traditionally inspired enterprise philosophy are becoming criteria for resource distribution in the EU cohesion policies. On the other hand, companies and in particular SME are reaching a paramount role as engines of the Internal market and European Integration. Acknowledgement of this fosters the granting of cohesion financial assistance to companies. It fosters too the introduction of new company governance and Social Corporate Governance systems which takes into account interests other than those of shareholders.

RÉSUMÉ: La programmation des aides structurales après 2007 montrent quel 'efficacité et competitivité, qui ont inspiré la philosophie d'entreprise sont aussi des critères pour la distribution des resources de cohesion structural europeenne. Les enterprises et particulièrement les Petites et Moyannes Enterprises sont en train d'avoir un rôle motriz pour l'integration européenne et pour le achemement du Marché interieur. La politique européenne de cohesion, en reconaissant cela assigne des resources structurelles a soutenir le development des entreprisees. De l'autre côté, l'importance des companies dans le dévelopement de l'Europe fait necessaire l'introduction et consolidation des nouveaux systèmes de governance des entreprises et de Responsabilité Social Corporative, que pour tenir en compte des interêts outres que ceux des accionistes.

* Doctora en derecho. Universidad de Santiago de Compostela.

Anuario Mexicano de Derecho Internacional, vol. VI, 2006, pp. $729-758$ 
SUMARIO: I. Marco actual en la historia de la Unión Europea. II. La "estrategia de Lisboa" y su renovación. Cohesión regional y acuerdos internacionales. III. Debate sobre la Agenda 2007, la cohesión territorial y las perspectivas financieras. IV. Cohesión territorial y empresa. V. Responsabilidad social corporativa. VII. Reflexiones.

\section{MARCO ACTUAL EN LA HISTORIA DE LA UNIÓN EUROPEA}

La naturaleza jurídico-política de la CE sugiere que estamos ante una forma de integración radicalmente distinta de cualquier intento anterior. Un sistema nuevo que además se manifiesta en pleno auge de la globalización y sin embargo responde a una lógica regional. ${ }^{1}$ Ahora más que hace pocos años, cuando el eje franco-alemán que ha regido los destinos europeos en los últimos años podría estarse debilitando a favor de la configuración de nuevas alianzas en torno al poder de países como Reino Unido y su área de influencia, el carácter dinámico de la Unión Europea se pone más que nunca de manifiesto.

La "integración" en el viejo continente anterior la década de los años cincuenta se había producido por métodos coactivos, ya fueran imperialistas o regalistas, a través de la invasión militar, o de las revueltas populares que dieron lugar al nacimiento de nuevas naciones o nuevas federaciones. En la Unión Europea no estamos, al menos por el momento, ante un sistema puro de integración federal. Frente a todos esos modelos, el comunitario es sui generis. Se ha desarrollado durante más de cincuenta años y se enfrenta ahora a nuevos retos derivados de la dinámica interna de la estructura de la Unión Europea, y de la dicotomía entre globalización y regionalización del "Nuevo desorden mundial" posterior a la caída del bloque comunista en 1989, al auge de las nuevas tecnologías y la ampliación al Este europeo.

El Tratado CEE de 1957 preveía la supresión de los derechos de aduana entre los Estados miembros, el establecimiento de un arancel aduanero exterior común; el establecimiento de políticas comunes en la agricultura y los transportes; la creación de un Fondo Social Europeo; o

1 Algunos autores contemporáneos han creído ver en el modelo europeo un ejemplo de cómo el fenómeno de la globalización es superado por el peso específico de los desarrollos regionales. En este sentido véase Torres Espinosa, Eduardo, "Integración europea y globalización. Una perspectiva institucional", Anuario Mexicano de Derecho Internacional, pp. 499-459. 
la constitución de un Banco Europeo de Inversiones, entre otras cuestiones. El mercado común debía garantizar una serie de libertades fundamentales: la libre circulación de las mercancías y la movilidad de los factores de producción (libre circulación de los trabajadores, libre prestación de servicios, libre circulación de los movimientos de capitales), y aunque en un principio no se señalara de forma tan clara como en la actualidad, cada etapa en el camino de la integración europea ha ido acompañada de medidas para favorecer la cohesión económica y social para contrarrestar los posibles efectos no deseados de la integración sobre determinados sectores económicos o regiones: Los trabajos para conseguir la unión aduanera y la puesta en práctica de la primitiva PAC en la década de los años sesenta, ya contenían una filosofía implícita de cohesión económica territorial social y sectorial. Las primeras ampliaciones hicieron más patente el substrato de solidaridad del proceso de integración del continente que se estaba gestando. ${ }^{2}$ En 1981 se adhiere Grecia, y en 1986 lo hacen Portugal y España. Las ampliaciones al sur a partir de 1981 pusieron en su día de manifiesto con más fuerza de lo que se había hecho nunca hasta este momento la necesidad de reforzar la solidaridad, y obligaron a realizar una revisión de los mecanismos de solidaridad territorial presentes hasta entonces en el derecho comunitario. Esta situación estaba coincidiendo con el gran impulso que Jacques Delors, entonces presidente de la comisión, estaba dando al proceso de creación de un mercado único. La reforma de los fondos estructurales que entró en vigor en 1989, ya contó con el fundamento jurídico con el Acta Única Europea. ${ }^{3}$

Desde mediados de 1980, la Unión Europea ha realizado avances muy considerables en su proceso de integración, con el establecimiento de un mercado interior en 1993 y con la introducción de la moneda única. Ha sido un periodo de considerable estabilidad macroeconómica, de inflación y déficit controlado.

Los tratados de la UE y de la CEE han consagrado la cohesión como uno de sus objetivos y misiones. En concreto, el artículo 2 TUE subraya que la UE debe promover el desarrollo equilibrado y sostenible, y el for-

2 En 1973 se incorporan al a Comunidad Económica Europea Irlanda Gran Bretaña y Dinamarca. En esa época se crea el FEDER o Fondo de Desarrollo Regional.

3 Para más detalles véase Pérez Carrillo, Elena F., "Cohesión y mercado en una europa ampliada", Anuario Mexicano de Derecho Internacional, vol. IV, 2004, pp. 519-544. 
talecimiento de la cohesión económica y social. ${ }^{4}$ Reitera la misión de promover un desarrollo armonioso, equilibrado y sostenible de las actividades económicas en el conjunto de la comunidad, un alto grado de competitividad y convergencia de los resultados económicos, elevación del nivel de vida, cohesión económica y social y la solidaridad entre los Estados El artículo 158 TCE establece que la comunidad se propondrá reducir las diferencias entre los niveles de desarrollo de las regiones y el retraso en las menos favorecidas. ${ }^{5}$ El Tratado "Constitución" que en estos momentos está en proceso de ratificación consagra en su artículo I-3 la cohesión territorial como objetivo de la unión.

La "gran ampliación" que se concretó el 1 de mayo de 2004 con el ingreso de 10 nuevos miembros del este y del sur de Europa, reforzó la necesidad de contar con instrumentos eficaces de cohesión. ${ }^{6}$ Este proceso

4 En el Proyecto de Tratado de "Constitución Europea" tal y como fue sometido a referéndum el 20 de febrero de 2005 en España tal artículo pasaría a situarse en el artículo I-3 de “Objetivos de la Unión".

5 Véase en sentido similar el artículo III-221 del Tratado de "Constitución Europea".

6 Durante la década de los noventa, la comunidad y sus Estados miembros celebraron diferentes acuerdos de asociación con diez países de Europa central, empezando por Hungría y Polonia en 1991. Tales acuerdos generales, conocidos como "Acuerdos Europeos" sentaron las bases jurídicas de las futuras relaciones bilaterales y fueron completados por protocolos sectoriales. El Consejo Europeo de Copenhague de 1993 abrió definitivamente el camino de la incorporación de los países del este del Europa a la Unión Europea y fijó los criterios fundamentales para la adhesión: estabilidad de las instituciones garantes de la democracia, Estado de derecho, respeto de los derechos humanos y protección de las minorías, economía de mercado, capacidad de soportar la presión de las fuerzas de la competencia y del mercado, y de asumir las obligaciones que requiere la calidad de Estado miembro. El Consejo Europeo de Essen, de finales de 1994 definió una estrategia de preadhesión basada en la aplicación de los Acuerdos Europeos, el programa Phare de asistencia financiera, y un dialogo estructurado. El Consejo Europeo de Madrid de diciembre 1995 volvió a incidir en las condiciones de la ampliación al este y en particular en el requisito de la adaptación de estructuras administrativas y la transposición del derecho comunitario a través de Instituciones estables. Los diez nuevos Estados miembros se benefician del apoyo comunitario. Durante el período 2000-2004 recibieron ayudas estructurales de conformidad con los instrumentos financieros de preadhesión ISPA (transportes y medio ambiente) y SAPARD (agricultura y desarrollo rural) y el programa Phare (refuerzo de las capacidades administrativas). 2004-2006 es un periodo de transición que les permitirá familiarizarse con la gestión de los fondos estructurales según las normas vigentes con anterioridad en los países miembros de la UE. Entre 2004 y 2006 los diez países adheridos en mayo de 2004 se beneficiaron del apoyo de los fondos estructurales por un importe total de 21800 millones a efectos de favorecer la construcción de infraestructuras, las inversiones en recursos humanos y las inversiones productivas. Sobre estas cuestiones, véase Pérez Carrillo, Elena F., "Unificación y cohesión del continente europeo, principales instrumentos jurídicos y económicos para la ampliación al Este". Anuario Mexicano de Derecho Internacional, vol. III, 2003, pp. 301-327. En estos momentos está prevista la aprobación de un nuevo instrumento de preadhesión que sustituya a SAPARD PHARE y ISPA, así como un instrumento de vecindad y cooperación. 
se había iniciado en 1993 en el Consejo Europeo de Luxemburgo, y en el Consejo Europeo de Copenhague, al fijarse los criterios para la adhesión, y culminó con la ratificación del Tratado de Adhesión o Tratado de Atenas. Algunos Estados habían propuesto en este panorama de "nueva Europa" poner coto al gasto en cohesión territorial, revertir esta política a la competencia estatal, e incluso permitir las trasferencias directas entre los Estados más ricos y los menos favorecidos para ahorrar los gastos de "fricción" derivados de la gestión de los fondos desde Bruselas. ${ }^{7}$ Finalmente no se han seguido esas propuestas, la política de cohesión sujeta a ciertas modificaciones va a seguir constituyendo una las piezas claves del entramado integracionista europeo, sin perjuicio de que en los próximos años algunos de los países receptores de ayudas para equilibrar su desarrollo podrían pasar a constituirse en contribuyentes a favor de Estados y regiones menos favorecidos que acaban de ingresar en la unión.

En la actualidad (2005 y 2006) nos encontramos en pleno periodo de debate del tratado conocido como "Constitución Europea", ${ }^{8}$ periodo que coincide con la preparación de nuevas propuestas financieras y de cohesión. El resultado negativo de los referenda de primavera de 2005 sobre los que incidiremos más adelante no obsta para que sea preciso reconocer que Europa pretende completar (con o sin texto constitucional) un proceso que tuvo su origen en el plano económico, y que progresivamente va alcanzado al plano político a través de la consolidación de unas libertades de mercado

El Tratado "Constitución", de futuro incierto en el momento de escribir estas líneas, se inserta en el proceso de reforma iniciada con Maas-

7 La ampliación europea, acogida con relativo optimismo plantea no obstante ciertos riesgos que dieron lugar al debate político en los primeros años del siglo XXI, entre los temores que suscitaba se encontraba el peligro de migraciones masivas, presión sobre los sistemas de empleo y seguridad social, la carestía de las trasferencias presupuestarias desde la comunidad a los nuevos miembros o la reducción de las inversiones de los fondos estructurales a los antiguos miembros de la EU-15. Véase Sapir, A. et al., An Agenda for a Growing Europe, The Sapir Report, Oxford, 2004, en particular p. 123. También Hartwig, I., "The Agenda 2007 Proposals: Evolution or Revolution", Eipascope, 2004, 2, pp. 2-8, en particular pp. 3 y 4.

8 Hemos "entrecomillado" el concepto puesto que, en realidad nos encontramos ante un nuevo tratado internacional, sin perjuicio de que lleve como título "Tratado por el que se establece una Constitución Europea". Esta denominación ha sido objeto de no pocas críticas y debates. Entre las posturas críticas que hemos encontrado más razonadas por partir de las diversas formas de entender o diversos conceptos de constitución véase Ruiz Miguel, Carlos, “¿Hacia el fin del derecho constitucional europeo?, Boletim da Facultade de Dereito, vol. LXXIX, 200, pp. 463-501. 
tricht en $1992^{9}$ y pretende dotar de renovado impulso al proceso de integración europea, aunque en opinión de algunos de sus defensores posiblemente será continuado por un proceso de cambios y adaptaciones que no permanecerán inalterados. ${ }^{10}$ Las principales reformas explícitas que se introducen con el Tratado de la Constitución Europea son de corte institucional, en una readaptación a la evolución histórica de la unión y en particular a la ampliación al Este de Europa: ${ }^{11}$ dotar de personalidad jurídica a la unión, ${ }^{12}$ fortalecer la política exterior y de seguridad, ${ }^{13}$ e introducir cambios en la denominación normativa ${ }^{14} \mathrm{y}$ en la delimitación de

9 Maastricht, Ámsterdam y Niza fueron dejando "flecos" en sus propios textos, que anunciaban en si mismos un nuevo tratado. Así lo expusimos, con más detalles en Pérez Carrillo, Elena F., "Más allá del mercado único. Algunas aportaciones del Tratado de Ámsterdam al lento proceso de integración europa", Revista de Estudios Europeos, núm. 22, mayo-agosto de 1999, pp. 69-88; "El Tratado de Ámsterdam. Entre el mercado de los quince y la Europa del siglo XXI", Noticias de la Unión Europea, pp. 171-180, y "El Tratado de Niza. Entre la consolidación de la Unión de Maastricht y el debate sobre el futuro de Europa", Anuario Mexicano de Derecho Internacional, vol. II, 2002, pp. 305-334.

10 Sobre este concepto de "Constitución inacabada", véase Martín y Pérez de Nanclares, J., El federalismo supranacional. ¿Un nuevo modelo para la Unión Europea?, Consejo Vasco del Movimiento Europeo, 2003, pp. 51-81, en particular p. 82.

11 Por lo que respecta a la Comisión Europea, las previsiones del Proyecto de Constitución son que hasta el 2014 se mantenga un Comisario por Estado y a partir de esa fecha reduzca su tamaño a un número de comisarios igual a dos tercios del número de Estados miembros, es decir, a dieciocho miembros en una unión de 27 Estados. Dentro de este número se incluye el presidente y el ministro de Asuntos Exteriores. Los comisarios serán elegidos conforme a un sistema de rotación igualitario, sin que ningún Estado pueda quedar excluido de contar con un comisario por un periodo superior a dos legislaturas. En el parlamento se vuelve a modificar el número máximo de miembros elevándose hasta 750 de forma que cada Estado cuente con un número comprendido entre los seis y los noventa y seis (España podrá elegir a 54 europarlamentarios hasta el ingreso de Bulgaria y Rumania en la unión, que supondrá la cesión de cuatro escaños a favor de esos nuevos socios. Con antelación suficiente a las elecciones del Parlamento Europeo de 2009 y siempre que sea necesario para comicios posteriores, el Consejo Europeo adoptará una decisión que establezca el reparto de los escaños de acuerdo en el principio de proporcionalidad.). El espinoso tema del voto en el seno del consejo parece haberse saldado con un difícil equilibrio basado en una doble mayoría que debe alcanzarse con un mínimo del $55 \%$ de los miembros del consejo, que comprenda al menos 15 de ellos y que represente a la vez $65 \%$ de la población. La minoría de bloqueo, por otra parte, debe estar compuesta por lo menos por cuatro Estados.

12 Se fusionan las personalidades jurídicas de las tres comunidades, para pasar a formar una personalidad única de la Unión Europea que permitirá la firma de tratados internacionales por parte de la Unión Europea.

13 El nuevo tratado pretende dotar de mayor visibilidad a la nueva PESC, permitiendo que la unión hable con voz única en el contexto internacional a través de una figura novedosa cristalizada en el cargo de ministro europeo de Asuntos Exteriores, que será además vicepresidente de la Comisión Europea, lo que supone una mejora significativa respecto del régimen anterior.

14 La simplificación normativa consiste en que se pasará de 15 a 6 instrumentos legislativos de derecho secundario, o fuentes de derecho comunitario derivado, y se les dota una nomenclatura más acorde con la tradición jurídica predominante en las tradiciones jurídicas de los Estados miembros. 
competencias con vistas a la simplificación y clarificación del marco jurídico. ${ }^{15}$ El proyecto de Tratado de Constitución Europea incluye varias propuestas de las regiones europeas que se reflejan desde los primeros artículos ${ }^{16}$ y que contribuirán a afirmar, en el plano del derecho primario, la necesaria cohesión territorial que debe inspirar la acción común. En concreto el artículo I-3 eleva la cohesión territorial a categoría de objetivo de la unión, artículo que se complementa con el III-221 a favor de la cohesión económica social y territorial que disminuya las disparidades en los niveles de desarrollo, con especial atención a las áreas rurales, áreas de transición industrial, áreas afectadas por limitaciones naturales o demográficas severas y permanentes (como las regiones del norte de la UE con baja densidad de población), así como las áreas insulares transfronterizas y montañosas. El artículo 5 propugna, junto con el respecto a la identidad nacional de los Estados miembros, el respeto a la autonomía regional y local. El artículo 89, junto con el Protocolo sobre la Aplicación de la Subsidiariedad y de la Proporcionalidad, extiende la aplicación de esos principios a los niveles regional y local. El nuevo tratado abre la posibilidad de que las propias regiones puedan verse asociadas al control de estos principios, control que será ejercido por los parlamentos nacionales. ${ }^{17}$ Por último, el artículo 22, consagrado al Consejo de Ministros mantiene la participación en sus reuniones a los representantes regionales con los mismos requisitos que se exigen en el Tratado de Niza, es decir que debe tratarse de un representante con rango ministerial y facultado para comprometer al Estado miembro. ${ }^{18}$

La simplificación alcanza además a los procedimientos de adopción de decisiones en aras de una mayor transparencia.

15 Se establece, siguiendo el mandato de Laeken, una diferencia entre competencias exclusivas de la unión, ámbitos de competencia compartida con los Estados miembros, y acciones de apoyo, coordinación y complemento.

16 Roeben, V., "Constitutionalism of Inverse Hierarchy: the Case of the European Union", Working Papers, Jean Monnet, http://jeanmonnetprogram.org, 2003, núm. 08/2003. Esta participación de las regiones en la gobernanza de la unión se relacionaría, a mi juicio con el substrato "inferior-estatal", al que se refiere la doctrina cuando alude a que Europea cuenta con una organización o gobernanza en varios niveles.

17 De esta forma, las regiones podrán actuar en la fase prelegislativa en el ámbito consultivo en coordinación con la Comisión Europea, en la fase de control ex ante de la subsidiariedad, asociadas a los parlamentos nacionales, y en la fase de control ex post interponiendo recursos en caso de violación a través del Comité de las Regiones. Gamallo Aller, J., “A Constitución Europea. Un paso adiante na construcción Política Europea”, Boletín Galicia Europa, núm. 149, 2004, pp. 3-5.

18 Corresponde a cada Estado miembro la articulación, si así lo desea, de un mecanismo que permita la presencia de representantes regionales en la delegación nacional que acudirá a las 
Como es sabido resultados negativos de los referenda de Francia (29 de mayo de 2005) y Holanda (1o. de junio de 2005) han abierto un debate en profundidad sobre la idea de los europeos respecto del futuro de la integración. Básicamente se abren dos vías de opinión en el espectro político:

- Por una parte la de aquellos que consideran oportuno ralentizar o suspender por completo los procesos de ratificación, línea liderada por el gobierno británico que anunció de inmediato la suspensión de su propio referéndum, que además está vertiendo nuevas y revolucionarias propuestas en relación con el presupuesto comunitario. El presidente de la Comisión Mario Barroso, así como el gobierno checo y buena parte de los partidos populares europeos se manifestaron en este sentido.

- Por otra parte, la de aquellos, como el gobierno español, el francés y el alemán y buena parte de los partidos socialistas europeos que abogaron, al menos en un primer momento por continuar con el procedo de ratificación para, entre otras cosas, no "devaluar" el "sí" español en su referendum de 20 de febrero de 2005.

Al margen de que en algún país haya continuado el proceso de ratificaciones, lo cierto es que entre los más fieles "adeptos" a la integración y entre los funcionarios europeos, los resultados de estos referenda han producido un fuerte impacto negativo de desasosiego y pesimismo. El no a la Constitución ha sido objeto de abundantísimos comentarios que se relacionan en buena medida con el hecho de que los ciudadanos de Francia y de Holanda hayan "castigado" el texto europeo como consecuencia de problemas de política interna (desempleo, crisis de liderazgo, inmigración, etcétera). Se dice que la línea de los que prefieren ralentizar el proceso constitucional de cara al futuro se relaciona con el "atlantismo" y las concepciones mercantilistas y económicamente liberales de lo que debería ser el proceso de integración. Se piensa, por el contrario, que aquellos que abogan por continuar las ratificaciones incluso a cambio de hacer concesiones o renegociar el tratado con los Estados que no lo han suscrito, se relaciona con el liderazgo del eje franco alemán que ha guia- 
do los destinos de Europa en los últimos años y que ha tenido su representación personal en el tandem Chirac y Schröeder, ambos en un periodo crítico en sus respectivas carreras políticas domésticas. La concesión de los Juegos Olímpicos de 2012 que puede verse como una victoria de Reino Unido sobre Francia en el campo de la política de influencias internacionales, y los atentados de Londres en 2005 constituyen elementos que, al menos en un plano psicológico, refuerzan el peso político específico de la línea atlantista dentro de la unión.

Pese a que nos encontramos obviamente ante un giro en la línea de construcción europea, estamos también en un excelente momento para recordar que, una vez superadas, las crisis suelen tener resultados positivos. El debate sobre el futuro que se inicia a raíz de las dos referenda citadas corresponde, en mi opinión, al que debería haberse verdaderamente originado a raíz de la compleja firma del Tratado de Niza y que sin embargo no caló suficientemente entre la ciudadanía del viejo continente. Recordemos que las instituciones europeas iniciaron una reflexión y que a raíz de la Declaración de Laeken de febrero de 2001 se abre el llamado "Debate sobre el futuro de Europa", y que se reflejó en el portal interinstitucional de la UE. Las pretensiones de políticos y funcionarios eran que aquel debate "dirigido" sirviese para despejar las opciones de desarrollo de la unión. En realidad, aquel intento no alcanzó a amplias capas de europeos que en cambio, si se han manifestado en un referéndum, posiblemente por causas divergentes, heterogéneas, significativamente relacionadas con la política nacional más que con la europea, pero que sin embargo confluyen en un aspecto: la necesidad de reflexionar en profundidad sobre el modelo europeo: no sólo el que deseen los políticos, sino el que prefieran los ciudadanos y el que estén dispuestos a pagar.

\section{LA "ESTRATEGIA DE LISBOA" Y SU RENOVACIÓN. COHESIÓN REGIONAL Y ACUERDOS INTERNACIONALES}

Junto con la Ampliación de 2004, y de forma paralela a ella, se están produciendo otros fenómenos que también impactan en el futuro de la política europea de cohesión. Uno de los más sobresalientes es el llamado "proceso de Lisboa".

El Consejo Europeo de marzo de 2000, Consejo de Lisboa, fijó como objetivo para la Unión Europea el llegar a ser la zona más competitiva y 
dinámica del mundo, basada en el conocimiento. ${ }^{19}$ Este objetivo, conocido como "estrategia de Lisboa", fue ampliado en el Consejo Europeo de Gotemburgo en el sentido de que la economía del conocimiento debe favorecer la puesta en marcha de políticas sociales y medioambientales que garanticen el desarrollo sostenible y la cohesión social. Se establecieron de esta forma en 2000 una serie de retos sobre la economía y sobre la sociedad europeas entre los que destacan los de alcanzar un nivel de empleo del $70 \%$, lograr un nivel de empleo femenino del 60\%, y conseguir incrementar de cara al 2010 un 50\% en el nivel de inversión en capital humano (educación, formación, salud, etcétera).

Entre los fundamentos del "Objetivo Lisboa" se sitúa la constatación de que Europa no puede hacer frente a la globalización, al reto tecnológico ni a la competencia de países de economías emergentes y bajos costes laborales como China o India a través del abandono de las políticas sociales, medioambientales o regionales, ni a través del cierre de sus fronteras. Por el contrario, la postura europea se basa en encontrar soluciones relacionadas con el refuerzo de la cohesión en el continente europeo, la responsabilidad social de las empresas, etcétera. Son soluciones coherentes con el concepto de desarrollo que se ha ido construyendo en Europa: el de dinamismo económico que impulse el crecimiento económico y social (por ejemplo, en términos de ocupación laboral de los trabajadores). El Objetivo Lisboa va incluso más allá de esa visión clásica en Europa, al propugnar la defensa del medioambiente y la cohesión, así como colocar a investigación y al desarrollo basado en la investigación, como motores del crecimiento. Lograr todos estos objetivos hace preciso atraer fondos, tanto del sector público, como del sector privado.

Pese a las intenciones plasmadas en Lisboa, el periodo de realización de estas propuestas está coincidiendo con una época de incremento del desempleo y de desaceleración económica en el viejo continente. De hecho, una de las críticas que se hacen al "Objetivo Lisboa" es que pudo haber sido el fruto de la euforia de un momento muy concreto: la época de finales de los años noventa, y del alza de las tecnologías de la información y la sociedad del conocimiento. No obstante, con el nuevo siglo no se han mantenido unas circunstancias que hayan favorecido alcanzar aquellos objetivos. En el plano mundial la explosión de la burbuja bursá-

19 Pérez Carrillo, Elena F. et al., "Europa XXI. Un espacio de investigación e de Coñecemento", Boletín Galicia Europa, núm. 106, 2000, pp. 2-7. 
til que hizo caer en picada las bolsas de valores y en particular los valores tecnológicos, y que además se vio acompañada por quiebras y escándalos derivados del descubrimiento de prácticas societarias fraudulentas, pusieron fin a una época de auge económico. Por otro lado, los atentados del 11 de septiembre de 2001 así como los atentados islámicos que se muliplicaron en todo el mundo, Europa incluida (atentados del 11 de marzo de 2004) contribuyen a crear un clima de inseguridad, pésimo para favorecer la inversión. ${ }^{20}$ En el plano interno, las disensiones y desavenencias en relación con la guerra de Irak y el enfrentamiento de "la vieja Europa" a EUA y sus aliados entre los que se encontraban todos los países del Este de Europa que en aquel momento se encontraban en pleno proceso de incorporación a la unión, contribuyó también a introducir inseguridades en el proceso de integración. ${ }^{21}$

Como consecuencia de los acontecimientos que han tenido lugar en el siglo XXI, la Unión Europea ha entrado en una fase de reestructuración económica, presupuestaria e incluso de sus tratados fundacionales, que hace preciso revisar los objetivos generales de cara a 2010.

En su informe de primavera de 2004, la Comisión Europea señaló que pese a que desde 2000 se habían logrado avances incuestionables en su camino hacia la competitividad, restaban retos y obstáculos muy importantes que obstaculizaban un pleno desarrollo. Se constituyó un grupo de alto nivel bajo la Presidencia de Win Kok en el que se ponía de manifiesto la importancia de contar con mayor grado de participación de los niveles locales y regionales en el desarrollo de la estrategia de Lisboa y Gotemburgo.22 Sobre estas bases, el 3 de febrero, la Comisión Europea aprobó una comunicación para su presentación al Consejo Europeo de Primavera de 2005 y que tiene por objeto la revisión de la estrategia de Lis-

20 Este terrorismo "islámico" se confunde en ocasiones con el global, es precisamente el terrorismo de tinte islamista el que más ha acentuado el uso de los medios violentos para crear terror. Sobre el concepto de terrorismo internacional véase Revilla Montoya, Pablo César, "El terrorismo global. Inicio, desafíos y medios político-jurídicos de enfrentamiento", Anuario Mexicano de Derecho Internacional, vol. 5, 2005, pp. 405-424. Para una visión analítica de los problemas derivados del "choque" de civilizaciones, en su manifestación sobre ciertos pueblos, véase Ruiz Miguel, Carlos, Anuario Mexicano de Derecho Internacional, vol. V, 2005, pp. 445-498.

21 En un excelente artículo en esta misma publicación se analizan críticamente las posturas ante la legalidad del proceso bélico, Bermejo García, Romualdo y Ruiz Miguel, Carlos, "La legalidad de la reanudación de la guerra de Iraq", Anuario Mexicano de Derecho Internacional, núm. IV, 2004, pp. 67-86.

22 Este informe se recoge en Rapport du groupe de haut niveau présidé par Wim Kok, M., La stratégie de Lisbonne pour la croissance et l'emploi, Bruselas, Relever de Défi, 2004. 
boa, su actualización y concreción. La comisión se proponer dar un nuevo punto de partida a la estrategia de Lisboa concentrándose en dos misiones principales que son reforzar el crecimiento duradero y crear mejores y más numerosos empleos. La puesta en marcha de esta "estrategia de Lisboa renovada" exige la formación de nuevas colaboraciones, tanto en el plano interno europeo como en el internacional.

La Unión Europea debe hacer frente a una evolución caracterizada por el contexto del desarrollo económico regido actualmente por la globalización y por la regionalización. Este cometido implica al menos una toma de conciencia sobre el hecho de que la innovación puede servir de motor del desarrollo económico, y de instrumento de relación, no sólo en el interior de la Unión Europea sino también en sus relaciones con terceros países, tanto países con un desarrollo tecnológico igual o superior al europeo, como en relación con las llamadas "economías emergentes".

Entre los aspectos en los que mayores perspectivas de innovación se están produciendo es el de la investigación y la sociedad de información, una de las que se deben reforzar según los objetivos de Lisboa. ${ }^{23}$ Puede constituir un elemento clave para incrementar la competitividad empresarial y reducir los desequilibrios. No obstante, en el plano interno de Europa, las regiones menos favorecidas suelen presentar debilidades estructurales. Las políticas europeas deben ocuparse del desarrollo de la sociedad de la información, tanto para consolidar una capacidad regional y equilibrar el desarrollo de infraestructuras de telecomunicaciones (redes de banda ancha, acceso, aplicaciones y servicios, instalaciones digitales y competencias), etcétera, como para desarrollar nuevas formas de organización estructural e institucional, y nuevos sistemas para fomentar la asignación de recursos. ${ }^{24}$

En relación con terceros países, a lo largo de los últimos diez años las instituciones comunitarias vienen adoptando posiciones favorables a la colaboración. Tal posicionamiento se ve plasmado en la conclusión de

23 Véase Pérez Carrillo y otros, Elena F., "Europa XXI: Un espacio de Investigación e de Coñecemento" Boletín Galicia Europa, núm. 96, 2000, pp. 2 y ss.

24 En una jornada mantenida por el presidente de la Comisión Europea el señor Barroso el día 31 de enero de 2005, este organismo recomendó que dentro del desarrollo de una política de innovación competitiva y eficaz como requiere la Agenda de Lisboa, es preciso fijar incentivos fiscales para que las empresas que inviertan en investigación (CES a Barroso el 31 enero 2005. Sugirió en concreto introducir deducciones fiscales de entre el 10\% y el 15\% de su inversión en I+D, justificando que sólo así se puede alcanzar el porcentaje del 3\% del PIB europeo en inversiones en investigación. 
acuerdos de cooperación científica y tecnológica, como por ejemplo el firmado entre la Comunidad Europea y los Estados Unidos Mexicanos. ${ }^{25}$ Este tipo de acuerdos sirven de base para el establecimiento y fortalecimiento de redes de alianzas entre centros, entidades de investigación y empresas situadas en países europeos y no europeos, para fomentar, desarrollar y facilitar actividades de investigación en los campos científicos y tecnológicos de interés común.

\section{DEBATE SOBRE LA AGENDA 2007, LA COHESIÓN TERRITORIAL Y LAS PERSPECTIVAS FINANCIERAS}

El 10 de febrero de 2004, la comisión adoptó una propuesta de perspectivas financieras de la Unión Europea ampliada a 27 Estados miembros (los quince, los diez nuevos Estados miembros, Bulgaria y Rumania ${ }^{26}$ para el periodo 2007-2013, reconociendo que la construcción de una Europa de extensión prácticamente continental debe respetar la diversidad cultural y nacional de los Estados, reivindicando al mismo tiempo la identidad europea y que constituye un desafío marcado por tensiones en el plano internacional y de incertidumbre en el plano interno.

La estructura general de las propuestas ha sido objeto de un intenso debate, que se une al derivado del intento de aprobar un tratado constitucional en Europa. Buena parte de las previsiones adelantadas por la comisión, en particular las correspondientes a ayudar a mantener la cohesión económica y social han sido matizadas y reducidas tanto por las presidencias luxemburguesa y británica. El Consejo Europeo de Bruselas de junio de 2005 sirvió para poner de manifiesto el desacuerdo entre países que pretenden mantener el gasto en cohesión, como España o Portu-

25 Este acuerdo se concluye a raíz de la presentación el 22 de enero de 2002 de una solicitud de acuerdo de cooperación científica y tecnológica por parte del embajador de México ante la UE que concluyo en el acuerdo rubricado el 2 de abril de 2003 en México y firmado el 3 de febrero de 2004.

26 La comisión presenta propuestas concretas que surgen del debate sobre el futuro de la política regional posterior a 2006. Propone un presupuesto para 2007-2013 equivalente al $0,41 \%$ del producto interior bruto (PIB) de la unión de 27 Estados miembros. Este porcentaje representa 336 300 millones de euros para el período citado. La comisión basa sus propuestas en la situación socioeconómica de la unión así como en el estudio del impacto de la política regional, las demás políticas europeas y las políticas nacionales. Comisión Europea, Comunicación "Construir nuestro futuro Común, retos políticos y medios presupuestarios de la unión ampliada (2007-2013). COM (2004) 101 final. 
gal, los que se aferran a la fuerte subvención a la agricultura europea como Francia o los que exigen que el Reino Unido renuncie a su famoso "cheque británico" pactado por el gobierno de Margaret Thacher y que supone la devolución anual a ese país de parte de sus aportaciones. Pese a que el debate no se cerrará por completo hasta bien entrado el 2006, y al margen de cual sea eventualmente el reparto de las cuantías que cada país aporte y de las ayudas que pueda recibir, creemos que se mantendrá la línea estructural adelantada por la comisión.

Las propuestas de la comisión, conocidas también como Agenda 2007, no sólo han resultado debatidas en 2005, sino también durante su elaboración interna. Deberían haber sido publicadas a finales de 2003, pero la dificultad por llegar a un consenso entre los miembros de la comisión presidida por Romano Prodi retrasó el acuerdo. Las tensiones entre los comisarios se saldaron en su mayor parte a puerta cerrada, pero es sabido que las perspectivas financieras están rodeadas de debates cuyo resultado podría afectar al núcleo de varias políticas europeas que consumen buena parte del presupuesto comunitario, y en particular de la política de cohesión, habiéndose incluso planteado la cuestión de su misma continuidad. ${ }^{27}$ Otro punto importante de divergencia lo constituye el límite máximo de aportación nacional al presupuesto comunitario.

Algunos Estados como Austria, Reino Unido, Holanda, Alemania y Suecia pretenden introducir el límite de un 1\% del Producto Interior Bruto, así como una reconfiguración del gasto en torno a dos objetivos principales: la competitividad, que en último término resulta del "objetivo Lisboa", y la cohesión. Mientras, otros países como Bélgica o Luxemburgo, así como el propio Parlamento Europeo se muestran más partidarios de establecer unos claros criterios políticos de reparto en lugar de reducir el gasto nacional.

Al tiempo que se producía el debate constitucional, y en la redacción del proyecto de Tratado Constitucional tuvo lugar la reformulación de los principales instrumentos de cohesión territorial de la unión. Una semana después de la publicación de las nuevas perspectivas financieras, en el mismo febrero de 2004, se publicó el Tercer Informe sobre la Cohesión Económica y Social en el que se plasman propuestas concretas

27 Hartwig, I., "The Agenda 2007 Proposals: Evolution or Revolution?", EIPASCOPE, 2004/2, pp. 3-8, en particular p. 3 . 
sobre la política regional europea posterior a 2006, en una Europa de entre 25 y 27 miembros. $^{28}$

De cara al futuro se establecen tres claros objetivos políticos en materia de cohesión, y sólo en segundo término entran a dilucidar los mecanismos financieros para su implementación. En virtud de tales objetivos, la Unión Europea debe contribuir a alcanzar un desarrollo sostenible, debe hacer realidad el concepto de ciudadanía y ha de desempeñar un papel importante en la escena mundial. ${ }^{29}$ En buena medida este programa responde al desarrollo del "Objetivo Lisboa", ${ }^{30}$ y a la culminación de dos procesos iniciados en la década de los años noventa, y con el Tratado de Maastricht, pero en los que aún se perciben fuertes deficiencias (ciudadanía y relaciones internacionales). ${ }^{31}$ Por lo que respecta a la política de cohesión, la escasez relativa de los fondos, junto con la necesidad de intervenir en las nuevas regiones del Este, sin abandonar las actuaciones en otras que siguen sin superar sus dificultades estructurales, hace que la política regional posterior a 2006 se concentre en un número limitado de temas clave, cuyos efectos se consideran multiplicadores de la inversión con el fin de equilibrar el desarrollo territorial.

La publicación de las propuestas legislativas de reglamentos para el nuevo periodo de política de cohesión en julio de $2004^{32}$ define lo que

28 Este informe puede consultarse en Comisión Europea, "Una nueva asociación para la cohesión, convergencia, competitividad cooperación, tercer informe sobre la cohesión económica y social", Bruselas, 2004.

29 Comisión Europea "Construir nuestro futuro común. Retos políticos y presupuestarios de la unión Ampliada (2007-2013). Com (004) 101 final, Bruselas, 2004. Se fijan tres objetivos para la Unión Europea ampliada: el desarrollo sostenible, el dotar de pleno contenido a la ciudadanía europea y el desarrollo de la UE como socio a escala mundial.

30 Seguramente sea el primer objetivo el más vinculado a la estrategia de Lisboa. Dar prioridad al crecimiento supone reorientar las políticas y los presupuestos nacionales y comunitarios, dinamizar y conectar mejor Europa a través de políticas de apoyo a la infraestructura física, a la empresa y la innovación, de creación de redes de apoyo a la educación, etcétera.

31 Dotar de contenido a la ciudadanía europea requiere reforzar la creación de un espacio de seguridad libertad y justicia que pasa por la gestión integrada de las fronteras exteriores, una política común en materia de asilo y una política común de integración, así como consolidar el acceso a los niveles de bienes y servicios básicos de interés general que se asocian al modelo económico y social europeo.

32 Propuesta de Reglamento sobre las disposiciones generales relativas al FEDER, al FSE y al Fondo de Cohesión de 14 de julio de 2004 COM (2004) 492 final. Propuesta de Reglamento relativo al FEDER de 14 de julio de 2004 COM (2004) 495 final. Propuesta de Reglamento del Parlamento Europeo y del Consejo relativo al Fondo Social Europeo de 14 de julio de 2004 COM (2004) 493 final; Propuesta de Reglamento del Consejo por el que se instituye el fondo de cohesión de 14 de julio de 2004, COM (2004) 494 final, Propuesta de Reglamento del Parlamento Europeo y del Consejo relativo a la institución de una agrupación europea de cooperación transfronteriza (AECT), 14 julio 
serán las bases de la nueva programación de ayudas de política regional. A partir de 2006 el énfasis de inversión de los fondos correspondientes a la política de cohesión se concentrará en el fomento, por una parte, la innovación y la economía del conocimiento; por otra parte el medio ambiente y la prevención de los riesgos; y por último la accesibilidad a servicios de interés general. Para aplicar estas prioridades, se han fijado tres ejes principales comunitarios, que sustituyen el reparto actual (objetivos $1,2,3) .{ }^{33}$ Además, se establecerá un programa específico para las siete regiones ultraperiféricas (RUP) (Guadalupe, Martinica, Guyana, Reunión, Canarias, Azores, Madeira), ${ }^{34}$ cuyo aislamiento repercute en contra de su desarrollo socioeconómico. ${ }^{35}$ Las RUP podrán optar a todos los objetivos de la futura política regional en función de su desarrollo y se beneficiarán de acciones adicionales en el marco de las demás políticas co-

2004 COM (2004) 496 final. Propuesta de Reglamento del Consejo relativo a la ayuda al desarrollo rural por el Fondo Europeo Agrícola de Desarrollo Rural de 14 de julio de 2004, COM (2004) 490 final, Propuesta de Reglamento del Consejo relativo al Fondo Europeo de Pesca de 14 de julio de 2004, COM (2004) 497 final.

33 Sobre estos objetivos véase Pérez Carrillo, Elena F., "Unificación y Cohesión del Continente europeo, principales instrumentos jurídicos y económicos para la ampliación al Este", Anuario Mexicano de Derecho Internacional, t. III, 2003, pp. 301-327.

34 La Unión Europea cuenta entre las regiones europeas con siete regiones ultraperiféricas: la Comunidad Autónoma española de las Islas Canarias; los cuatro departamentos franceses de ultramar: Guadalupe, Guyana, Martinica y Reunión; las regiones autónomas portuguesas de las Azores y Madeira. El reconocimiento en el apartado 2 del artículo 299 del Tratado de un estatuto específico de la ultraperiferia se funda en los principios de igualdad y proporcionalidad, permite tratar de manera diferente la situación distinta de estas regiones. Las regiones ultraperiféricas padecen las dificultades específicas enumeradas en el Tratado- lejanía, insularidad, reducida superficie, relieve y clima adversos, dependencia económica de un reducido número de productos, factores cuya persistencia y combinación perjudican seriamente a su desarrollo. Poseen características comunes que acentúan su aislamiento y fragilidad las condiciones socioeconómicas de su desarrollo (en particular, la escasísima diversificación económica orientada principalmente al turismo y la agricultura). Desde la aplicación de los programas de medidas específicas para combatir los problemas derivados de la lejanía y la insularidad (POSEI) en 1989 y 1991, las regiones ultraperiféricas han sido objeto de medidas específicas basadas, por una parte, en el reconocimiento de las particularidades de estas regiones y, por otra parte, en el objetivo de su desarrollo socioeconómico en aras de la convergencia y la integración con relación al resto de la Unión Europea. Puede consultarse una síntesis sobre las propuestas específicas en COM (2004) 343 final, Comunicación de la Comisión, Estrechar la asociación con las regiones ultraperiféricas Bruselas, 26.5.2004.

35 Está previsto que las regiones ultraperiféricas puedan optar a cada uno de los objetivos en función de su nivel relativo de desarrollo Aunque aún estamos en una etapa previa, habida cuenta de las tendencias que se perfilan en sus niveles de desarrollo actuales, todas las regiones ultraperiféricas deberían poder optar a la futura política de cohesión, bien conforme al objetivo de convergencia bien al de competitividad regional y empleo, y serán beneficiarias del objetivo de cooperación territorial europea. 
munitarias. ${ }^{36}$ Además, la comisión aporta dos respuestas específicas destinadas a que se desarrolle plenamente el Programa Específico de Compensación de Condicionantes ${ }^{37}$ y el Plan de Acción para la Gran Vecindad. ${ }^{38}$

El objetivo "convergencia" apoyará el crecimiento y la creación de empleo en las regiones menos desarrolladas, desplegando sus efectos en regiones de nivel Nuts II (que coincide en términos generales con las divisiones políticas de las regiones o en España, de las Comunidades Autónomas cuyo PIB per cápita sea inferior al $75 \%$ de la media de la unión de 25 , a las que se destinará el $78 \%$ del presupuesto de la futura política regional. Proporcionará hasta 2013 una ayuda transitoria a las regiones que "salen" del antiguo objetivo 1, por un simple efecto estadístico. ${ }^{39}$ Podrán beneficiarse de las ayudas derivadas de este objetivo aquellas empresas destinadas a dar prioridad a la innovación, a poner en práctica los resultados del I+D europeo y a lograr un mercado de trabajo integrado. El refuerzo de la política de creación de empleo cualificado demuestra la coherencia de este objetivo con la estrategia de Lisboa

El segundo objetivo, u objetivo de "competitividad regional y empleo", estará orientado a dinamizar el tejido económico de acuerdo con los objetivos de Lisboa y Gotemburgo, es decir, con la configuración de una economía competitiva basada en el conocimiento, en un progreso duradero y respetuoso con el ambiente. La comisión propone que este objetivo cuente con el $18 \%$ de la dotación presupuestaria procedente a partes iguales del FEDER y el FSE. Las ayudas que reciban las regiones que se sitúen en este objetivo estarán muy vinculadas a la mejora de la competencia y competitividad de la mano de obra europea, una mayor intensi-

36 Por ejemplo, está previsto que la comisión estudie los costes adicionales de las RUP en el acceso a las telecomunicaciones, etcétera. Véase http://europa.eu.int/comm/regional_policy/Themes/rup es.htm

37 El "Programa especifico de compensación de los condicionantes se financiará integralmente por el Fondo de Desarrollo Regional (FEDER) y se dedicaría a reducir los problemas específicos que afectan a la economía de las RUP: lejanía, insularidad, escasa superficie, relieve y clima difíciles y dependencia económica respecto de un reducido número de productos.

38 El Plan de Acción para la gran Vecindad se destina a reducir las barreras que limitan las posibilidades de intercambio de los países europeos con sus nuevos vecinos, así como de las regiones ultraperiféricas muy distantes del continente europeo pero muy próximas África o a América, por tanto está integrado fundamentalmente por medidas transfronterizas. Véase Sapir, A. et al., An Agenda for a Growing Europe, The Sapir Report, Oxford, 2004, pp. 143 y ss.

39 Al ser el PIB de la unión de 25 inferior al PIB de la unión de 15, algunas regiones que actualmente pueden optar al Objetivo $n^{\circ} 1$ dejarán de cumplir el criterio de subvencionabilidad. 
dad de las inversiones y una mayor utilización de las tecnologías de información y comunicación, es decir, coincide también con los objetivos de Lisboa. La distribución de los créditos entre los Estados miembros se realizará sobre la base de criterios económicos, sociales y territoriales fijados a escala europea. En este apartado, la comisión propone un doble enfoque, a la vez regional y nacional.

Los programas regionales permitirán anticipar mejor el cambio económico. Respaldados exclusivamente por el FEDER, irán dirigidos a las regiones actualmente seleccionables para el objetivo núm. 1 y que dejarán de estar incluidas en él, así como a las regiones que no se incluyen en los programas de convergencia. ${ }^{40}$

Los programas nacionales reforzarán la aplicación de la Estrategia Europea del Empleo. Sostenidos exclusivamente por el FSE, se concentrarán en la adaptación de la población activa a los cambios en el trabajo (formación permanente), promoción del empleo y lucha contra la salida precoz del mercado laboral (envejecimiento activo, mayor participación de las mujeres), empleo de las categorías en dificultad (personas discapacitadas, minorías étnicas).

Por último, la comisión propone crear un nuevo objetivo de "cooperación transfronteriza, transnacional e interregional" que se beneficiará de un 3,94\% de los créditos de la política regional. Este objetivo de cooperación territorial europea que se financiará con cargo al FEDER reunirá acciones que se basan en la larga y positiva experiencia de la iniciativa Comunitaria Interreg y servirá para fortalecer e incrementar la cooperación transfronteriza a través de programas conjuntos, cooperación a escala de zonas trasnacionales, redes de cooperación y de intercambio de experiencias, etcétera. ${ }^{41}$ Todo el territorio de la unión podrá verse beneficiado de la financiación de redes de cooperación e intercambio ya que la cooperación transfronteriza abarcará las regiones situadas a lo largo de las fronteras terrestres interiores y de algunas de las exteriores, así como de algunas fronteras marítimas y contribuirá a acciones que se realicen

40 Una característica básica de las regiones objetivo 1, y en delante de las regiones europeas del objetivo "convergencia" es que muestran un PIB inferior al 75\% de la media comunitaria.

41 La cooperación transfronteriza entre los Estados europeos cuenta ya con una larga tradición, como lo tiene el apoyo recibido por los fondos estructurales. Sobre sus antecedentes véase Fernández Fernández, Loreto y Vidal Portabales, Ignacio, "La cooperación empresarial transfronteriza ante el escenario de 1992. Breve referencia a la Sociedad Anónima Europea", Euro 15, núm. 55, 1992 pp. 1-5. 
en virtud de dos nuevos fondos que se van a implantar también a partir de 2006: El instrumento europeo de vecindad y cooperación (que consituye un fondo específico para colaborar en la modernización de los países vecinos de la Unión Europea), ${ }^{42}$ y del instrumento de preadhesión (a favor de los países candidatos a futuras incorporaciones). ${ }^{43}$ La creación de redes de cooperación que se basaran en buena medida (aunque no exclusivamente) en las Tecnologías $\mathrm{I}+\mathrm{C}$ y se espera que contribuirán a desarrollar la sociedad del conocimiento dentro y fuera de las fronteras europeas, contribuyendo también a alcanzar el Objetivo de Lisboa.

Las ayudas con cargo a los fondos estructurales seguirá siendo vital en todo el continente europeo pero además resultará esencial en los próximos años, para reforzar la competitividad de los nuevos Estados miembros y para su convergencia con occidente. La necesidad de desarrollar un enfoque estratégico y de centrar la atención en un núcleo reducido de prioridades, de garantizar la máxima coherencia entre los fondos estructurales y las políticas nacionales tanto en el ámbito de planificación como de ejecución, constituyen los principales retos de la integración europea en los próximos años. Hay que esperar, no obstante, al resultado final de las negociaciones plurianuales sobre perspectivas financieras para averiguar si la programación de fondos estructurales y de cohesión futura seguirá contando con un volumen de inversión significativo con el fin de continuar reduciendo las diferencias entre las regiones. Las perspectivas financieras se sitúan en la base del reto de cohesión europea en este momento.

Por lo que respecta a España, la política de cohesión de la Unión Europea articulada a través de los fondos estructurales y del fondo de cohesión ha sido muy beneficiosa. ${ }^{44}$ Aún nos encontramos en fase de defini-

42 Ya nos referíamos a los fundamentos y a los primeros estudios que fundamentan este mecanismo en Pérez Carrillo, Elena F., "Unificación y cohesión del continente europeo, principales instrumentos jurídicos y económicos para la ampliación al Este", Anuario Mexicano de Derecho Internacional, t. III, 2003, pp. 301-327.

43 Una vez aprobado el nuevo Instrumento de vecindad y cooperación, y el nuevo instrumento de preadhesión sustituirán a otros programas actuales como son Phare, Tacis, MEDA, Cards, ISPA y Spaard.

44 Un reciente estudio señala que las ayudas recibidas entre 1989 y 2006, que alcanzaron casi 100.000.000 euros a precios de 1999 han mantenido la tasa de crecimiento real del PIB 0,4 puntos porcentuales por encima de la que hubiese existido en su ausencia. Las ayudas comunitarias habrían contribuido a la convergencia real de España con la media europea en casi 6 de los 15 puntos en los que se ha incrementado el PIB por habitante desde 1989. Estos datos son recogidos por los autores 
ción de los detalles sobre la financiación comunitaria para el periodo 2007-2013, pero ya se puede adelantar que nos enfrentamos a cambios: el efecto estadístico de la ampliación, el avance del PIB español de los últimos años y el límite de financiación comunitaria del 1,24\% del PIB comunitario implican que inevitablemente las ayudas que reciba nuestro país vayan a verse sustancialmente reducidas. Caben varias interpretaciones a la propuesta de la comisión de marzo de 2004 pero en su conjunto podría implicar que de 60.200.000.000 euros a precios de 2004 que se aprobaron con la agenda 2000 para el periodo $2000-06,{ }^{45}$ se puede pasar a un a cifra sólo ligeramente superior a la mitad esa cifra. Parece definitivo que Castilla u León, Canarias y Valencia (por convergencia real) y Asturias, Murcia, Castilla-La Mancha y Ceuta y Melilla (por convergencia estadística a raíz de la ampliación de 2004) dejarán de percibir ayudas del objetivo 1, y pasarán a recibir ayuda transitoria hasta 2013. Parece también que Cantabria dejará de recibir las ayudas transitorias que tenía concedidas hasta 2006. De esta forma, sólo permanecerán dentro del objetivo de convergencia (ex objetivo 1) Andalucía y Extremadura.

Por lo que respecta a Galicia, se sitúa (tomado como referencia del cálculo el periodo que termina en 2003) precisamente en torno a un $74.5 \%$ del PIB, por lo que el retraso en la adopción de una decisión definitiva sobre perspectivas financieras (que supone que en lugar de tomarse como referencia los datos económicos hasta 2003 se incluya 2004) puede hacer de esta una de las regiones más perjudicadas. ${ }^{46}$

Las repercusiones para España de las reducciones que se vayan a recibir de los fondos estructurales pueden resultar muy graves. Aun a expensas de que se producen las decisiones finales, la perspectiva es que de un saldo de recepción de 48.715 millones de Europa en el periodo comprendido entre 2000 y 2006, España pase a recibir únicamente $5.000 \mathrm{mi}-$

del estudio en El País, 8 febrero 2005, Secc Economía, p. 64; S. Sosvilla Rivero, Ja Herce, "España ante el futuro de la política de cohesión comunitaria".

45 Pérez Carrillo, Elena F., "A Política regional europea e as intervencións estructurais en Galicia cara ao periodo 2000-2006. Algunhas reflexións", Boletín Galicia Europa, núm. 96, 1999, pp. 2-7.

46 Consultando en las hemerotecas la actualidad de febrero de 2005 podemos constatar el debate que ha surgido como consecuencia de ciertos datos publicados por Eurostat u oficina Estadística Europea en virtud de los cuales la Comunidad Autónoma de Galicia superaría en algunas décimas el límite del 75\% del PIB comunitario, lo que supondría una pérdida del estátus del objetivo de convergencia. Por el contrario las autoridades nacionales y autonómicas insisten en que se trata de un error y en que se mantendrán las ayudas correspondientes al antiguo objetivo 1. 
llones para todo el periodo $2007-2013,{ }^{47}$ tal y como se propuso en el fallido Consejo Europeo de junio de 2005. Este cambio tan repentino significa pasar de recibir una media de casi 7.000 millones de euros anuales que suponen un $0,91 \%$ del PIB español, a sólo $714(0.08 \%$ del PIB español). Y lo que es más, se prevé que a partir de 2013, España pase a ser un contribuyente neto al presupuesto comunitario. Este cambio puede ser percibido como que cada español vaya a contribuir con unos 661 euros durante el periodo 2007-2013 a financiar la ampliación, pese a que los estudios previos a que este hecho tuviese lugar no parecían haberlo puesto en evidencia. 48

La disminución en fondos europeos, que se completa porque España dejará de recibir fondo de cohesión (dedicado a la financiación de infraestructuras y proyectos medioambientales) según se consagra en el protocolo 29 del Proyecto de Tratado, puede tener unas consecuencias muy graves sobre la economía y sobre el empleo en España y en muchos países de Europa.

\section{COHESIÓN TERRITORIAL Y EMPRESA}

El Tratado de Roma y el establecimiento de una Comunidad Económica Europea han resultado beneficiosos para el desarrollo empresarial europeo. El Informe Ceccini de 1988, o estudio sobre los efectos de la "no Europa" llegó a la conclusión de que la no-consecución del pleno mercado interior, y de la eliminación de barreras (defensa de la libre competencia, armonización de estándares técnicos, plena liberalización de los controles transfronterizos, etcétera) estaba impidiendo alcanzar el máximo desarrollo posible en Europa. Este informe sirvió de base para el lanzamiento del libro verde de Delors que a su vez constituye el origen de 300 medidas legislativas para alcanzar el mercado único. No obstante, incluso si se progresa adecuadamente en la integración del mercado inte-

47 Actualización de las perspectivas financieras de la comisión para el periodo 2007-2013 de 17 de diciembre de 2004.

48 En Pérez Carrillo, Elena F., "Unificación y cohesión del continente europeo, principales instrumentos jurídicos y económicos para la ampliación al Este", Anuario Mexicano de Derecho Internacional, t. III, 2003, pp. 301-327, señalabamos que las autoridades comunitarias habían insistido en que la ampliación al Este no supondría una drástica reducción de las ayudas a las regiones europeas que, pese a la contribución de la política regional en los últimos años no hubieran logrado alcanzar plena convergencia. 
rior, subsisten disparidades regionales inaceptables, desequilibrios que repercuten en las empresas instaladas en las regiones más desfavorecidas. Ello implica que junto con las medidas generales tendentes a la consecución del mercado interior, son necesarias otras específicas relativas a lograr evitar el aislamiento, desequilibrios e imperfecciones del mercado derivados de la variedad geográfica que compone el continente europeo. Precisamente en atención a esta circunstancia, algunas de las ayudas estructurales están destinadas específicamente a favorecer el mercado a través del apoyo a las empresas y a los agentes sociales ubicados en determinadas regiones.

La programación de las inversiones con fondos estructurales ha tenido muy presente la relevancia de las empresas como motor de multiplicación de los efectos de inversión. Estas ayudas pueden adoptar diferentes formas, y dirigirse tanto a pequeñas como a grandes sociedades. ${ }^{49}$ En la mayoría de los casos se traducen en asistencia financiera, ayudas a la formación y a la innovación o apoyo a la creación y al desarrollo de empresas. Por lo que se refiere a estas últimas, sólo entre 1989 y 1999, 1,5 millones de pequeñas y medianas empresas, es decir, el $8 \%$ del total de las

49 Junto con los fondos estructurales dedicados directamente a favorecer a las empresas, existe otro tipo de apoyo financiero público cuya legitimidad está seriamente limitada por los tratados europeos y puede ser contrario a los objetivos de Lisboa: las ayudas de Estado. Sin embargo, en tanto que tengan como objetivo contribuir a incrementar el crecimiento, la competitividad y el desarrollo sostenible, ambas políticas (regional y de defensa de la competencia) resultan complementarias a otras políticas de integración. Las ayudas concedidas por los Estados a las empresas, incluso si estas operan en sectores desfavorecidos, se someten a las normas de la política de competencia de la Unión Europea. Los Estados miembros han reducido sus ayudas estatales y las han reorientado hacia objetivos horizontales de conformidad con las estrategias generales de la UE. El control de la concesión de ayudas estatales tiene efectos muy positivos sobre la política de cohesión si se articula para concentrar las ayudas en determinadas regiones y para reducir las disparidades regionales en la UE. En 2001 se destinaron unos 8 billones de euros (un 9\% del total), en concepto de ayudas de Estado a las regiones clasificadas (a efectos de competencia) como del tipo "a", que prácticamente coinciden con lo que serían regiones objetivo 1, en términos de política regional. Aunque globalmente este porcentaje se había mantenido a lo largo de los años anteriores, en 2001 se produjo una desconcentración en el sentido de que las ayudas abarcaron mayor numero de regiones, y en cambio se redujeron las que estaban desatinadas a los antiguos Länder de Alemania del Este, y que eran las que más se habían beneficiado de importantes sumas en los dos años inmediatamente posteriores a la reunificación. Por otro lado, también en 2001 se asignaron unos 800 millones de ayudas estatales ( $\sin$ incluir las ayudas en pesca, agricultura y transporte) a las regiones que a efectos de política de competencia se denominan "c" y que en buena medida coinciden con las que se insertan en el objetivo 2 de los fondos estructurales en política regional. Adicionalmente, otros 4,5 millones de euros se destinaron a regiones "c", dentro de NUTS 2 que recibían al menos parte de ayuda del objetivo 2. Al no contar con datos sobre unidades territoriales de dimensiones inferiores a los NUT 2, no es posible evaluar si tales ayudas beneficiaron exactamente a las mismas zonas favorecidas por los fondos estructurales. 
PYME se beneficiaron de una ayuda de los fondos estructurales. Durante el periodo plurianual de programación 1994-1999 las empresas de pequeño y mediano tamaño se beneficiaron de casi un 5\% del total de las intervenciones de los fondos estructurales, y las grandes empresas también participaron de estas ayudas, así como de la gestión de proyectos. ${ }^{50}$ En el periodo 2000-2006 se confirmó esta prioridad, de forma que unos 21 millardos de euros fueron destinados exclusivamente al apoyo directo a las PYME. ${ }^{51}$

En el periodo 2006-2013 vamos a ver, además, que se fortalece la canalización de fondos a proyectos gestionados por empresas, y en especial pequeñas y medianas o PYME. ${ }^{52}$ Ahora bien, estas ayudas deben tener en cuenta cual es el efecto multiplicador de la acción empresarial y cual es su impacto sobre la cohesión, en especial en un momento en el que las cuantías de los fondos públicos disminuyen dramáticamente.

50 Ernst \& Young Evaluación temática de los Fondos Estructurales en las PYME, 1999, http://www.inforegio.cec.eu.int/wbdoc/docgener/evaluation/sme/index_en.htm.

51 Comisión Europea, "Construir una Europa empresarial", Actividades a favor de la pequeña y mediana empresa (PYME) 2000, Bruselas, 2001, pp. 79 y ss. Hay que recordar, no obstante, que de conformidad con el reglamento marco de fondos estructurales para el actual periodo de programación, Reglamento 1260/1999 (DO L 161 de 26.6.1999 la intervención de los fondos (inversión directa en empresas) se sometió a límites del 35\% del total del coste subvencionable en las regiones del objetivo 1, y el 15\% en las del objetivo 2. La normativa de 1999 supuso un refuerzo del análisis estratégico por lo que se solicitaron descripciones cuantificadas de la situación de las empresas en cada región. Según el artículo 41 del Reglamento 1260/1999 la evaluación previa debe tener en cuenta la situación de las PYME y las recomendaciones de evaluaciones anteriores. Durante este periodo, los Estados también debieron de respetar, en sus actuaciones estructurales, las directrices de la comisión en relación con la intervención estructural 2000-2006 (se pueden consultar

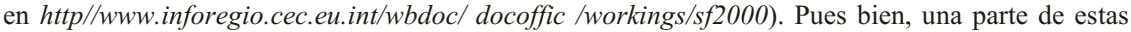
directrices está dedicada al apoyo de las empresas (incluidos jóvenes empresarios, mujeres empresarias y microempresas), al turismo y a la economía social. Estas actividades contribuyen a la creación de puestos de trabajo y ala competitividad de las economías regionales.

52 Las PYME son frecuentemente reconocidas como objetivo prioritario en muchos programas que a menudo incluyen medidas a su favor, teniendo en cuenta la contribución que aportan a la realización de la cohesión. Esta orientación es ya clásica, aunque se refuerza en cada periodo de programación de acciones de cohesión. El Tribunal de Cuentas, en su informe anual de 1997 (correspondiente al periodo de 1996) recomendó incrementar la visibilidad de las acciones estructurales a favor de las PYME (DO C de 18.11.1970. El Parlamento Europeo también ha insistido en la necesidad de mejorar la orientación de los Fondos Estructurales a favor de las PYME en su Resolución de 4.11.1998 sobre la coordinación de las actividades a favor de las PYME y la artesanía. 


\section{RESPONSABILIDAD SOCIAL CORPORATIVA}

Las empresas pueden constituir elementos de fomento de la cohesión social y al equilibrio territorial, pero para ello deben asumir su lugar en la sociedad no como meros multiplicadores de rendimientos económicos a favor de sus accionistas, sino como entidades que se integran en la sociedad a la que pertenecen, de cuyos activos se nutren y a la que aporta riqueza; como organización con una responsabilidad frente a los trabajadores, proveedores, etcétera..$^{53}$

Frente al modelo estadounidense de empresa de finales del siglo XX, que se orienta prioritariamente a la maximización de beneficios, el modelo europeo se considera más vinculado al respeto de los intereses diversos que confluyen en ella la empresa, a proteger a los "interesados diversos" o Stakeholders y además de, obviamente, producir beneficios a los accionistas o Shareholders. ${ }^{54}$ Esta tendencia tendría su origen en la época posterior a la Segunda Guerra Mundial, cuando la Sociedad Anónima se concibe como un instrumento para lograr la recuperación frente al deterioro causado por la conflagración.

No toda la doctrina ha estado de acuerdo en esta orientación, pero al margen de las tendencias, la idea del componente social de la propiedad de las acciones ha estado presente en mayor o menor grado en todos los

53 La Comunicación de la Comisión relativa a la responsabilidad social de las empresas: una contribución empresarial al desarrollo sostenible, COM (2002) 347 de 2.07.2002 trata sobre la dimensión social y ambiental de las empresas en una economía mundializada y condujo a la creación de un Foro multilateral europeo para promover la aprobación voluntaria por las empresas de prácticas sociales y ambientales vinculadas a sus principales actividades y que van más allá de sus obligaciones legales.

54 Se dice que frente ala doctrina predominante en las empresas norteamericanas de finales del siglo XX de "maximización del valor (a corto plazo) del accionista, en Europa suelen tenerse en cuenta con mayor nitidez y efectividad la concurrencia de otros intereses, de lo tros interesados o Stakeholders. Véase Silacuse, J. W., "Corporate Governance, Culture and Convergence", European Business Law Review, 2003, pp. 471-496, en particular p. 485). Incluso en Reino Unido, país cuyo derecho de sociedades presenta muchos paralelismos con el de EEUU, algunos renombrados autores han abogado por el reconocimiento de intereses ajenos a los de los accionistas, en este sentido véase Gower (véase Girón, J., Las grandes empresas, Valladolid, 1965, p. 80.) Sin embargo a medida que se desarrollan los mercados de valores europeos en especial a partir de la década de los años ochenta adquiere fuerza la idea de la sociedad como entidad para maximizar el valor de las acciones. Sobre estas cuestiones Ferrarini, G., "Shareholder value and the Modernisation of European Corporate Law", en Hopt, K. J. y Wymeersch, E. (coords.) Capital Markets and Company Law, Gante 2002. pp. 229 y ss. 
países europeos ${ }^{55} \mathrm{y}$ de forma muy evidente. En el contexto comunitario europeo, con el cambio de siglo, y en buena medida a raíz de los sucesivos escándalos financieros que se producen a ambos lados del atlántico (Banesto, Enron Worlcom, Parmalat) se está volviendo a fortalecer el movimiento a favor del reconocimiento de la responsabilidad social de las empresas. Se están despertando expectativas y deseos de transformación de su función, en consonancia con el mensaje de la estrategia de desarrollo sostenible del Consejo Europeo de Gotemburgo de junio de 2001.

Las empresas europeas deben contribuir al crecimiento macroeconómico a largo plazo. Ello exige aunar el desarrollo de intereses económicos medioambientales, de cohesión social, y de incrementar las exigencias de transparencia en la adopción de decisiones.

La responsabilidad social de las empresas (RSE) es un concepto conforme al que éstas integran los criterios sociales y ecológicos en sus actividades comerciales y empresariales, así como en sus relaciones con terceros. Son prácticas que se basan, al menos por el momento en instrumentos jurídicos voluntarios basados en que el éxito comercial y los beneficios duraderos para los propietarios y accionistas se maximizan con un comportamiento responsable orientado a favorecer el crecimiento económico y la competitividad, al tiempo que protegiendo el medio ambiente y otros intereses como los de los consumidores.

En julio de 2001 la comisión presentó su libro verde "Fomentar un marco europeo para la responsabilidad social de las empresas". ${ }^{56}$ En este documento se define RSE como "la integración voluntaria por parte de las empresas de las preocupaciones sociales y medioambientales en sus operaciones comerciales y en sus relaciones con sus interlocutores". La Comisión Europea, en plena época de escándalos financieros y empresa-

55 En Europa se desarrollan con mayor intensidad las teorías institucionalistas sobre la personalidad jurídica societaria, y en particular, sobre la relevancia de esta para, a través de sus fines, promocionar el interés social, incluso por encima de los intereses particulares o egoístas de sus accionistas. En este contexto se sitúan los escritos de Rathenau, sobre la "empresa en sí misma" o de Netter sobre el interés por conservar la empresa incluso a costa de alienar los intereses de los accionistas. También en esta línea se sitúan ciertos escritos de Keynes sobre la evolución de la Sociedad anónima y la trasformación del sistema económico en su discurso en la Universidad de Munich de 1926 titulado "El fin del laissez faire...". Estas corrientes doctrinales hacen que se conceda más importancia al "prestigio empresarial", a la "creación de grandes empresas" que a la maximización de valor bursátil. Véase Velasco, G. Esteban, El poder de decisión en las sociedades anónimas. Derecho europeo y reforma del derecho español, Madrid, 1972, pp. 130 y ss.

56 Comisión Europea, COM (2001) 366 final. 
riales, planteó así una serie de retos sobre la necesidad de que las empresas participen en la construcción de una mejor sociedad, y propugna el debate sobre la responsabilidad social. La Comisión Europea propugnó de esta forma la "asociación de objetivos e intereses" entre empresas mercantiles y la comunidad en general que se basaría en el convencimiento de que los beneficios duraderos no se obtienen únicamente con una maximización de los resultados a corto plazo, sino con un comportamiento que orientado al mercado, sea además responsable, y sirva para fomentar el desarrollo sostenible, la protección del medio ambiente o los intereses de los consumidores. Frente a anteriores iniciativas europeas socialmente responsables la Comisión Europea señala que el actual movimiento se distingue porque pretende poner ese elemento como un elemento estratégico. ${ }^{57}$

La RSE responde a cuestiones esenciales como el reto de la globalización que crea nuevas oportunidades pero también incrementa la complejidad organizativa y la necesidad de reforzar el prestigio como elemento de la competitividad. Se entiende que las empresas que cumplan sus requisitos contribuirán al funcionamiento sostenible de los mercados comerciales. En el plano europeo comunitario se promueven las prácticas de RSE en las que la participación de la Unión Europea suponga una ventaja, es decir, se plantean dentro del respeto de la subsidiariedad. ${ }^{58} \mathrm{El}$ elemento de voluntariedad implica que para ser socialmente responsable no sólo se han de cumplir plenamente las obligaciones jurídicas sino que se ha de ir "más allá" invirtiendo en el capital humano, el entorno y las relaciones con los interlocutores. Esta voluntariedad no actúa, no obstante, para eliminar las normas imperativas que rigen el funcionamiento empresarial. Lo que es más, se considera que en los países donde las empresas carezcan de un marco estable, el primer esfuerzo hacia la eventual responsabilidad social pasa por instaurar un marco mínimo normativo. ${ }^{59}$

Las prácticas de RSM se basan en aprovechar las oportunidades de la globalización, por lo que deberían trascender el mero ámbito de la empresa "aislada", para alcanzar también a sus filiales y subcontratistas, y deberían formar parte de un esfuerzo concertado de todos los implicados

57 Comisión Europea, COM (2002) 347 final, "Comunicación relativa a la responsabilidad social de las empresas: una contribución empresarial al desarrollo sostenible", p. 6.

58 Comisión Europea, COM (2002) 347 final, p. 9.

59 Comisión Europea, Libro verde "Fomentar un marco Europeo para la responsabilidad social de las empresas", Bruselas, 18.07.2001. COM (2001)366 final. 
con miras a objetivos comunes, así como incluir el dialogo civil y social de conformidad con los usos y legislación nacionales alcanzado, así como una cierta repercusión geográfica regional. Además estas prácticas no pueden olvidar determinados aspectos internos, en particular la salud y seguridad en el trabajo y la gestión de recursos humanos. ${ }^{60}$

La estrategia europea de RSE exige la implicación de agentes sociales, empresarios, Estados, instituciones, etcétera, en el objetivo de lograr un desarrollo sostenible y equilibrado, así como la integración en el mismo de todas las políticas de la unión. ${ }^{61} \mathrm{~A}$ tal fin la comisión se ha comprometido a crear un grupo inter servicios con el objeto de intercambiar información y garantizar la coherencia entre las diversas acciones en este ámbito, al menos en los terrenos de la política de empleo y asuntos sociales, la política ambiental, ${ }^{62}$ la protección de los consumidores, la contratación pública, la política exterior y la acción de las diversas administraciones públicas. ${ }^{63}$

De lo indicado hasta aquí se deduce que puede distinguirse una perspectiva externa de la RSE, y otra interna, y que la Unión Europea cuenta con una estrategia específica para fomentar ambas.

En el aspecto externo, la RSE se proyecta sobre las comunidades locales y regionales, y afecta a un amplio abanico de interlocutores, desde los socios comerciales a los proveedores, consumidores, autoridades pú-

60 Resolución del Consejo de 6 de febrero de 2003 relativa a la responsabilidad social de las empresas (DOC2003).

61 Comisión Europea. Dirección General de Política Regional, Las políticas estructurales y los territorios europeos, competitividad, desarrollo sostenible y cohesión en Europa. De Lisboa a Gotemburgo. 2003, p. 11, recuerda una concisa definición de desarrollo sostenible como "un desarrollo capaz de responder a las necesidades actuales sin comprometer la capacidad de las generaciones futuras a responder a las suyas.

62 A raíz de la aprobación del Tratado de Ámsterdam en 1997, la promoción de un "desarrollo armonioso, equilibrado y sostenible de las actividades económicas se añadió a los objetivos de la unión, véase sobre esta cuestión Pérez Carrillo, E. F., "Más allá del Mercado Único. Algunas aportaciones del Tratado de Ámsterdam al lento proceso de integración europea", Revista de Estudios Europeos, núm. 22, 1999, pp. 69-88. El impacto del desarrollo sobre el medio ambiente alcanza a varios elementos desde el cambio climático (reducción de gases de defecto invernadero, fomento de la utilización de energías renovables, etcétera), reducción del transporte de mercancías por carretera reorientándolo a otros medios interrumpiendo el incremento de contaminación sonora y atmosférica, etcétera.

63 Comisión Europea. Comunicación relativa a la responsabilidad social de las empresas: una contribución empresarial al desarrollo sostenible, Bruselas 2 .07.2004, COM (2002) 347 final, pp. 21-27, Comisión Europea, "LA prevención y la gestión del cambio: Un enfoque dinámico sobre los aspectos sociales de la reestructuración de empresas", COM (2002) 118 final, Comisión Europea Comunicación "Cómo adaptarse a los cambios en la sociedad y en el mundo del trabajo: una nueva estrategia comunitaria de salud y seguridad (2002-2006), COM (2002) 118 final. 
blicas, las ONG, etcétera. Las empresas contribuyen al desarrollo de las sociedades en las que se sitúan creando puestos de trabajo, salarios, ingresos fiscales, etcétera, al tiempo que manifiestan una fuerte dependencia del entorno en el que se sitúan, por ejemplo de la salud de sus habitantes, la estabilidad y prosperidad de la comunidad, etcétera. Por otra parte, la reputación de la empresa en su entorno, su imagen como empresario y como agente local también influye en su competitividad. Uno de los componentes esenciales de la RSE es el medioambiental. La disminución de consumo de recursos o de producción de desechos y emisiones contaminantes reduce el impacto negativo de la actividad económica sobre el medio ambiente y puede además ser ventajosa para la reducción de gastos energéticos de la empresa. ${ }^{64} \mathrm{La}$ RSE es también importante como elemento de gestión social de los cambios. En Europa se vienen produciendo reestructuraciones importantes a lo largo de los últimos 25 años. Son procesos que generan distensiones importantes entre los trabajadores y en el seno de la sociedad en general. Las medidas que se sitúan en el núcleo de las reestructuraciones como el cierre de plantas, recortes en el empleo o en la protección social, tienen el potencial de provocar crisis económicas sociales o políticas graves, y lo que es peor, frecuentemente no logran sus objetivos. ${ }^{65}$

En la dimensión interna, las prácticas de RSE afectan a sus trabajadores y a otros componentes del ciclo productivo. Permiten abrir nuevas vías de administración de los recursos, nuevos regímenes de gobernanza,

64 Así ha sido reconocido en el Sexto Programa Marco de Medio Ambiente de la UE (2000-2010), que en este aspecto resulta complementario con la estrategia de RSC y contempla medidas dirigidas a las empresas, tanto para que comprendan y cumplan los requisitos de la Unión Europea, como para la elaboración e intercambio de buenas prácticas en el ámbito local, regional, nacional y europeo que fortalecen la coordinación y la cooperación entre las empresas de los distintos Estados miembros. Así ha sido reconocido en el Sexto Programa Marco de Medio Ambiente de la UE (2000-2010), que en este aspecto resulta complementario con la estrategia de RSC y contempla medidas dirigidas a las empresas, tanto para que comprendan y cumplan los requisitos de la Unión Europea, como para la elaboración e intercambio de buenas prácticas en el ámbito local, regional, nacional y europeo que fortalecen la coordinación y la cooperación entre las empresas de los distintos Estados miembros.

65 En torno a un $25 \%$ de los procesos de reestructuración empresarial no logran sus objetivos, precisamente porque una vez finalizados se ha dañado la moral, la motivación, la lealtad, la creatividad y la productividad de los trabajadores La reestructuración responsable debe pasar por tener en cuenta las necesidades, intereses y preocupaciones de todos los afectados por los cambios y las decisiones. Debe contar con la participación y la implicación de todos ellos mediante una información y una consulta abiertas, y responden a un programa ordenado en el que se hayan identificando los riesgos más importantes, calculado todos los costes y evaluado todas las opciones. 
de gestión del cambio; así como conciliar el desarrollo social con el incremento de la competitividad. Uno de los desafíos a los que se enfrentan las empresas es el de atraer a trabajadores cualificados y lograr que permanezcan a su servicio. Para alcanzarlo, las medidas de RSE podrían situarse en el aprendizaje permanente, mayor equilibrio entre familia, trabajo y ocio, mayor diversidad de recursos humanos, participación en los beneficios y en el accionariado de la empresa, etcétera. Además, las prácticas responsables de contratación, y en particular el fomento de la no-discriminación facilitan la incorporación a la empresa de personas pertenecientes a minorías étnicas, trabajadores de edad, minusválidos, etcétera, y tienen un efecto directo en los objetivos como la reducción del paro y la lucha contra la exclusión social. En el ámbito del aprendizaje permanente, las empresas deben desempeñar un papel fundamental, contribuyendo a definir las necesidades de formación mediante una estrecha asociación con los agentes locales que diseñan los programas de educación y formación, fomentando el acceso de los jóvenes al empleo y su incorporación a la vida laboral. ${ }^{66}$ Otro ámbito en el que se proyecta la faceta interna de la RSE es el de la salud y la seguridad en el trabajo, perspectivas en las que tradicionalmente se ha actuado únicamente en cumplimiento de leyes imperativas. Las empresas, los gobiernos y organizaciones profesionales están cada vez mas interesados en establecer sistemas complementarios de promoción de la salud y la seguridad utilizándolas como condiciones para adquirir productos y servicios de otras empresas y para promocionar sus propios productos o servicios. Las acciones voluntarias complementan la normativa y las actividades de control de las autoridades públicas.

\section{REFLEXIONES}

Nos encontramos, con toda claridad, en un momento clave para el futuro de la integración en Europa. El rechazo al Tratado de Constitución en las referenda de Francia y en Holanda, dos países fundadores de la CEE y dos contribuyentes netos a las arcas comunes, han constituido un punto de inflexión importante en el proceso de construcción de Europa. Por encima de todo, debe servir para reflexionar sobre la necesidad de re-

66 Libro verde "Fomentar un marco Europeo para la responsabilidad social de las empresas", Bruselas, 18.07.2001. COM (2001)366 final, p. 9. 
formular las relaciones entre los Estados y entre las regiones de una unión que ya cuenta con 450 millones de habitantes y se encuentra en pleno periodo de expansión.

Las nuevas perspectivas financieras y la nueva política de cohesión posterior a 2006, constituyen los grandes retos de una nueva etapa en la integración europea del siglo XXI. Los debates promovidos a comienzos de la década actual por las propuestas de algunos de los Estados más poderosos, están poniendo en tela de juicio las bases generales de la política de cohesión vigente en Europa desde 1988. A mi juicio esto es consecuencia del hecho de que la ampliación de 2004, la que se espera de cara a 2007, no ha hecho sino acentuar las divergencias regionales y el incremento de población que se está produciendo en Europa como consecuencia de la inmigración, está afectando a la confianza de los europeos. Creo no obstante, que la política de cohesión seguirá constituyendo un pilar básico en la construcción de Europa.

En otro orden de cosas, la renovación en 2005 de la Estrategia de Lisboa, que pretende hacer de Europa la sociedad más dinámica del mundo basada en el conocimiento, consolida la necesidad de incorporar definitivamente nuevos elementos en el sistema de cohesión de la unión. Para mantener la solidez del sistema europeo es preciso reforzar la competitividad del continente, tanto a través de alianzas estratégicas con países externos, como a través del fortalecimiento de la responsabilidad social de las empresas. 